\title{
DOE/PC/91305--12
}

DE-FG22-91PC91305-12

\section{CHARACTERIZATION OF POROSITY VIA SECONDARY REACTIONS}

J.M. Calo (Principal Investigator) and L. Zhang

Division of Engineering

BROWN UNIVERSITY

Providence, Rhode Island 02912

Quarterly Technical Progress Report

1 July 1994 - 30 September 1994

Prepared for:

U.S. DEPARTMENT OF ENERGY

Pittsburgh Energy Technology Center

Pittsburgh, Pennsylvania 15236

["US/DOE Patent Clearance is not required prior to the publication of this document."] 


\section{Disclaimer}

This report was prepared as an account of work sponsored by the United States Government. Neither the United States, nor the United States Department of Energy, nor any of their employees, makes any warranty, express or implied, or assumes any legal responsibility for the accuracy, completeness, or usefulness of any information, apparatus, product, or process disclosed, or represents that its use would not infringe privately owned rights. 


\section{DISCLAIMER}

Portions of this document may be illegible in electronic image products. Images are produced from the best available original document. 


\section{SUMMARY}

The following was accomplished during the reporting period:

- Comparisons between porosity characterization data obtained from nitrogen adsorption isotherms, and that revealed by $\mathrm{CO}$ and $\mathrm{CO}_{2}$ TPD spectra were performed for Pittsburgh \#8 coal char samples prepared at various degrees of burn-off, ranging from $0-72 \%$ burn-off, in $0.1 \mathrm{MPa}$ oxygen at $470^{\circ} \mathrm{C}$.

- Conclusions derived from these analyses include:

- The CO TPD spectra correlate the development of the microporosity.

- The $\mathrm{CO}_{2}$ spectra correlate the development of the larger, external porosity.

- This behavior is the same as we have observed for Wyodak coal char.

- This behavior is currently attributed to the restriction of formation of the larger $\mathrm{CO}_{2}$-liberating oxygen surface complexes (e.g., lactones, carboxylic acid anhydrides) to the larger, external porosity, while the smaller $\mathrm{CO}$ liberating complexes (e.g., carbonyls, semi-quinones) form on the surfaces of all they porosity, but since the microporosity accounts for the bulk of the surface area, the latter correlates the microporosity quite well.

- Together with the Wyodak coal char results, these data represent the first time that this particular connection has been made between porosity development and TPD spectra.

\section{Plans for the next reporting period:}

Plans for the next reporting period include obtaining additional TPD spectra of the oxygen-gasified chars. To the chars already examined, we will add phenolformaldehyde resin char. The nature of the secondary interactions (i.e., secondary $\mathrm{CO}_{2}$ formation and $\mathrm{CO}$ rechemisorption) will be further investigated primarily via studies of the behavior of these features as a function of heating rate. 


\subsection{PROJECT BACKGROUND}

\subsection{Overview.}

Specific surface area, as well as its accessibility to gaseous reactants, are of paramount importance for all heterogeneous interactions occurring at coal char surfaces. Accessibility of this surface area is governed by the pore structure morphology of the char; i.e., pore size distribution, tortuosity, intersections, shape, etc. The porosity morphology of coal chars varies over a considerable range and is determined by a large number of factors including the nature of the porosity of the precursor material prior to carbonization, the carbonization process, and extent and method of any subsequent activation or gasification. A persistent problem in this area has been the reliable, quantitative measurement and characterization of the resultant porosity, especially the micropores. For example, electron microscopy tends to be qualitative; small angle X-ray or small angle neutron scattering (SAXS/SANS) can suffer from sensitivity to interpretive models, and the inability to distinguish porosity that communicates with the surface from that which does not; and gas adsorption techniques also have several well known drawbacks. The latter, however, are perhaps the most reliable in general, but yield pore size distributions indirectly via surface area and pore volume measurements, and can also be laborious and time-consuming. Therefore, there is still a critical need for practical and facile techniques to characterize the porosity of coal chars.

\subsection{The Current Project.}

The current project is directed at the development of a new approach to this very old problem. During the course of recent work applying temperature programmed desorption (TPD) to the determination of energetic distributions of oxygen complexes on the surfaces of oxidized coal chars (Calo et al., 1989, 1991), we discovered that secondary interactions occurring within the char structure during 
TPD produce characteristic features in the resultant spectra that appear to be quite sensitive to char porosity. The relative and absolute extents of these secondary interactions form the basis of a potential characterization technique. The use of such a method to characterize coal char porosity is potentially attractive because the requisite spectra can be obtained in a single TPD experiment -- a very facile experimental procedure. However, the unambiguous and quantitative interpretation of such data in terms of parameters that can be used to characterize coal char porosity still requires development and an improved understanding of the controlling phenomena. These issues define the primary focus of the current work.

The background and general approach of the secondary interaction method for the characterization of porosity was outlined in the first quarterly technical progress report on this grant (DE-FG22-91PC91305-1), and, therefore, it will not be repeated here. Here we report on the progress that has been made in the construction, development and testing of a new TPD-MS/TGA system being developed in our laboratory for the purpose of conducting the temperature programmed desorption experiments for obtaining the secondary interaction data.

The project plan also includes the use of other techniques to characterize porosity in addition to the secondary interaction approach for the purposes of comparison, quantification, and validation. It is noted that at least two other more well established methods will be used in such a manner. Specifically, gas adsorption techniques in our own laboratory, and small angle scattering (SAS) (X-ray (SAXS) and, possibly, neutron (SANS)). The latter will be accomplished in conjunction with Dr. Peter J. Hall of the Department of Pure and Applied Chemistry of the University of Strathclyde, Glasgow, Scotland. It is planned to obtain small angle Xray scattering data on the coal chars that will be used in our project via access to a small angle $X$-ray scattering system available in his department. As currently envisioned, Dr. Hall and his co-workers will obtain the X-ray scattering data, and we will analyze these data using models and computational techniques being developed in our laboratory. 


\subsection{PROJECT WORK}

\subsection{The Relationship Between TPD Spectra, Burn-off and Porosity.}

\section{1-1. Experimental}

The char samples used in the current experiments were prepared from Pittsburgh \#8 bituminous coal samples obtained from Argonne Premium Coal Sample Bank (Vorres, 1993). Pyrolysis was performed in a tube furnace in flowing, ultrahigh purity helium for two hours at $1000^{\circ} \mathrm{C}$. Small samples (on the order of 20$60 \mathrm{mg}$ ) from larger batches of char prepared in this manner were used for each run in the TPD-MS/TGA system.

All the oxidation and thermal desorption experiments were carried out in the new TPD-MS/TGA apparatus that has been under development in our laboratory. This system was constructed from a Cahn D-200 digital recording microbalance. The TPD reactor is the "hangdown" tube for the microbalance. The system can operate under vacuum conditions to atmospheric pressure, and the coal char sample can be prepared, oxidized, and thermally desorbed without exposing the samples to the ambient atmosphere.

The samples were burned off in pure oxygen at $0.1 \mathrm{MPa}$ at selected temperatures. The thermal desorptions were all carried out at a heating rate of $50 \mathrm{~K} / \mathrm{min}$ to $1200^{\circ} \mathrm{C}$ in a carrier gas flow of ultrahigh purity helium which passes over the sample in downflow. The pressure in the hangdown tube during these experiments was about 20 torr.

Detection of desorbed species was accomplished with a quadrupole mass spectrometer(MS) which samples a small portion of the carrier flow. The MS output is fed to a computer which also provides for multispecies detection via mass programming. The mass spectrometer was calibrated prior to each TPD run using pure $\mathrm{CO}_{2}$ and $48 / 52 \mathrm{~mol} \% \mathrm{CO} / \mathrm{CO}_{2}$ mixture in order to determine relative species sensitivity. 
Nitrogen adsorption isotherms for the coal char samples were obtained using a Quantachrome Quantasorb surface area analyzer with nitrogen at $77 \mathrm{~K}$ as the adsorbate.

\section{1.-2. Porosity Development Via $\mathrm{N}_{2}$ Adsorption Isotherms.}

The previous technical quarterly report (DE-FG22-91PC91305-11) focused on the development of porosity with burn-off of Wyodak coal char. The current report extends the discussion to Pittsburgh \#8 coal char.

The nitrogen desorption isotherm data presented in Figures 1 and 2 indicate that these two coal chars develop porosity differently. The distinctive Type I isotherm behavior for the Wyodak coal char at low burn-offs indicates that this particular char already has significant microporosity at zero burn-off. As burn-off proceeds, it develops additional microporosity, as well as significant mesoporosity, as indicated by the Type II behavior with a relatively steep linear portion for $\mathrm{p} / \mathrm{p}^{\circ}>$ 0.3 . This region becomes steeper with burn-off, indicating continued development of porosity in this size range.

As shown in Figure 2, however, Pittsburgh \#8 coal char initially exhibits practically no porosity, and thereafter develops porosity over the entire spectrum of pore sizes, including the microporosity. However, it never develops the microporosity to the degree evident for the Wyodak char,

These observations are reflected in the pore size distributions obtained from these nitrogen isotherms. A method devised by Roberts (1967), as modified by Gregg and Sing (1982), is adopted for this purpose. In this method, the pore system is divided into 13 groups, in order to achieve a fairly uniform spacing in relative pressure, from mean pore radii of $100 \AA$ to $17 \AA$. Allowance is made for the progressive thinning of the multilayer adsorbate in each pore as desorption proceeds. The calculation is best done in a tabular form. Consequently a spreadsheet template was developed for this purpose. A copy of the resultant template for a 
Pittsburgh \#8 sample burned-off to $15 \%$ is presented as Appendix A.

The resultant pore size distributions for the Pittsburgh \#8 and Wyodak coal char samples as a function of burn-off are presented in Figures 3 and 4, respectively. As indicated by these plots, the Pittsburgh \#8 coal char develops a greater mesoporous fraction than the Wyodak char, and its microporosity never approaches the level of development evident for the Wyodak.

Another method of separating adsorption in micropores from that in the larger porosity of carbons and chars is the so-called $\alpha_{\mathrm{s}}$-plot method (Lippens et al., $1964,1965)$. This technique is based on a direct comparison of the shape of the adsorption isotherm of a sample with that of a standard nonporous reference material. First, the adsorption data of the sample and the reference are each normalized by $n_{s}$, the amount adsorbed at a fixed relative pressure, usually $\left(\mathrm{p} / \mathrm{p}^{\circ}\right)_{\mathrm{s}}=$ 0.4. The sample adsorption data are then re-plotted $v$ s. $\mathrm{n} / \mathrm{n}_{0.4}\left(=\alpha_{\mathrm{S}}\right)$ to construct a so-called $\alpha_{s}$-plot. The transformation of independent variable from $\mathrm{p} / \mathrm{p}^{\circ}$ to $\alpha_{\mathrm{s}}$ is effected using the $\alpha_{\mathrm{s}}$-curve of a reference material. If a straight line through the origin results, the isotherm is identical in shape with the reference. The extrapolated slope of the first few experimental points at low $\mathrm{p} / \mathrm{p}^{\circ}$ provides the total surface area, the slope of the upper linear branch gives the nonmicroporous surface area, and the extrapolation of this branch to $\alpha_{\mathrm{S}}=0$ provides the total micropore volume.

$\alpha_{s}$-plots were constructed for all the nitrogen adsorption isotherms for the all the Pittsburgh \#8 samples using data for the standard nonporous carbon proposed by Rodriguez-Reinoso et al. (1987). The corresponding $\alpha_{\mathrm{S}}$-plots for the Pittsburgh \#8 coal char samples are presented in Figure 5.

Corresponding surface areas and pore volumes were also obtained via comparison to the isotherm for the reference adsorbent given by Rodriguez-Reinoso et al. (1987), following the data work-up procedures contained therein. The resultant variation in surface areas with burn-off for the Pittsburgh \#8 coal char samples.are presented in Figure 6. As shown, both the total and micropore surface areas initially increase with increasing burn-off and then pass through maxima 
around $30 \%$ burn-off. This behavior is qualitatively similar to that of the Wyodak coal char, which is presented in Figure 7, although of course, the porosity of this latter char is considerably greater at all levels of burn-off. The same general behavior has been observed for many other carbonaceous materials as well (e.g., Miura and Hashimoto, 1984; Walker, 1986). When compared to total surface area and porosity, it is evident that micropore development and subsequent collapse controls the overall qualitative behavior resulting in the maximum.

\section{1-3. Porosity Development Via TPD.}

The $\mathrm{CO}$ and $\mathrm{CO}_{2}$ TPD spectra for the Pittsburgh \#8 coal char samples are presented in Figures 8 and 9, respectively, as a function of burn-off. These spectra are qualitatively similar to those obtained for the Wyodak samples ( $c f$. Figures 10 and 11), but they are quantitatively quite different.

The CO spectra in Figures 8 and 10 both appear to exhibit at least two principal desorption features; one centered $c a .750^{\circ} \mathrm{C}$, and the other closer to $1000^{\circ} \mathrm{C}$. However, the two features are much more separated for the Pittsburgh $\# 8$ than for the Wyodak samples. The higher temperature peak is somewhat obscured in the Pittsburgh \#8 spectra by the high temperature tail which we have attributed to $\mathrm{CO}$ evolution due to interaction of the sample with the quartz sample bucket.

A similar situation exists with respect to the $\mathrm{CO}_{2}$ spectra in Figures 9 and 11 . That is, the spectra for both coal chars appear to exhibit at least two features, although the first feature may be composed of at least two peaks which overlap extensively. In both cases, the higher temperature feature appears to be considerably sharper, and becomes more distinct and intense with burn-off. The increase in intensity most probably accounts for its apparent steady shift to higher temperatures with burn-off.

The first major desorption peak evident was fit to Gaussian peak shapes, adopting the method proposed by Calo et al.(1989,1991): viz., 


$$
I=I_{o} \exp \left\{-\left[\left(T-T_{m}\right) / \sigma\right]^{2} / 2\right\}
$$

where $T$ is the temperature, $T_{m}$ is the mean temperature at the peak, $I_{o}$ is the maximum desorption rate, and $\sigma$ is the variance of the Gaussian. For the data presented here, the units of $\mathrm{I}$ and $\mathrm{I}_{\mathrm{O}}$ are $\mathrm{mmol} / \mathrm{g}$.min.

The total amount of desorbed gas, $\mathrm{M}_{\mathrm{G}}(\mathrm{mmol} / \mathrm{g})$, represented by the Gaussian distribution is simply the integral of Eq.[1], or:

$$
\mathrm{M}_{\mathrm{G}}=(2 \pi)^{1 / 2} \mathrm{I}_{\mathrm{o}} \sigma / \beta
$$

where $\beta$ is the linear heating rate in ${ }^{\circ} \mathrm{C} / \mathrm{min}$. The parameters extracted from these fits, along with the integrals of the TPD spectra are summarized in Table I.

Table I. Gaussian fits to CO TPD data for Pittsburgh \#8 coal char.

\begin{tabular}{cccccccc}
\hline \hline $\begin{array}{c}\text { Burn-off } \\
(\%)\end{array}$ & $\begin{array}{c}\text { Total CO } \\
(\mathrm{mmol} / \mathrm{g})\end{array}$ & $\begin{array}{c}\text { Total } \mathrm{CO}_{2} \\
(\mathrm{mmol} / \mathrm{g})\end{array}$ & $\begin{array}{c}\mathrm{M}_{\mathrm{G}} \\
(\mathrm{mmol} / \mathrm{g})\end{array}$ & $\begin{array}{c}\mathrm{I}_{\mathrm{o}} \\
(\mathrm{mmol} / \mathrm{g} \min )\end{array}$ & $\begin{array}{c}\mathrm{T}_{\mathrm{m}} \\
(\mathrm{K})\end{array}$ & $\begin{array}{c}\sigma \\
(\mathrm{K})\end{array}$ & $\phi \times 10^{3}$ \\
\hline \hline 5 & 0.645 & 0.137 & 0.50 & 0.10 & 736 & 105 & 3.1 \\
16 & 0.766 & 0.143 & 0.60 & 0.11 & 733 & 106 & 0.66 \\
30 & 1.15 & 0.234 & 0.87 & 0.16 & 735 & 106 & 0.94 \\
45 & 0.908 & 0.258 & 0.67 & 0.13 & 743 & 106 & 5.6 \\
60 & 0.925 & 0.258 & 0.65 & 0.11 & 750 & 118 & 3.3 \\
73 & 0.855 & 0.305 & 0.46 & 0.08 & 760 & 120 & 4.3 \\
\hline \hline
\end{tabular}

As shown in Figure 12, the total desorbed $\mathrm{CO}$, and specific surface area for the Pittsburgh \#8 coal char samples exhibit similar trends with burn-off. On the other hand, as shown in Figure 13, both the total amount of $\mathrm{CO}_{2}$ desorbed and the 
external surface area both follow similar trends with burn-off.

One possible explanation for these results that we are exploring is that intrinsic CO-liberating oxygen surface groups (e.g., carbonyls, semi-quinones) form over the entire accessible surface area of the coal char, while the $\mathrm{CO}_{2}$-liberating groups (e.g., lactones, carboxylic acid anhydrides) are prohibited from forming anywhere but in the larger external porosity -- this argument is related to a molecular sieve effect. Otake and Jenkins (1993) have shown that the $\mathrm{CO}_{2}$-liberating oxygen surface complexes present on their oxidized carbon samples were responsible for the acidic nature of the surfaces, and that $\mathrm{CO}_{2}$ evolution results primarily from thermal decomposition of carboxylic acid groups. This identification of surface species is also consistent with a considerable amount of other work in the literature. For example, Starsinic et al. (1983) identified similar surface species via FTIR spectroscopy. The size of the carboxylic acid anhydride groups would prevent their formation on microporous surfaces, while the smaller carbonyl and semiquinone oxygen surface complexes, which are responsible for most of the $\mathrm{CO}$ evolution can form over the entire accessible surface area of the char. This picture is also consistent with the increasing amount of external porosity with burn-off which can host the larger, $\mathrm{CO}_{2}$-liberating complexes.

Another check on this hypothesis lies in a comparison between the behavior of $\mathrm{CO}$ desorption and the micropore surface area. It has been shown that in cases where carboxylic anhydride complexes are present that high temperature $\mathrm{CO}_{2}$ evolution is primarily due to the thermal decomposition of these surface complexes. The stoichiometry for the decomposition of these surface groups is $1: 1 \mathrm{CO}: \mathrm{CO}_{2}$. Therefore, the contribution to $\mathrm{CO}$ desorption from these groups can be corrected for by subtracting the $\mathrm{CO}_{2}$ evolution from the $\mathrm{CO}$ evolved. This has been done in Figure 14, where the amounts of desorbed gases have been normalized to the micropore surface area at $15 \%$ burn-off. As shown, although the correlation between the micropore surface area determined from the $\alpha_{s}$-plots and the CO desorption is improved somewhat by this correction, the agreement is still not exact, 
so definitive conclusions cannot be drawn from just these data.

\section{1-4. Summary and Conclusions.}

Oxygen surface complexes created on Pittsburgh \#8 char samples during gasification in oxygen are essentially completely decomposed by heat treatment to $1200^{\circ} \mathrm{C}$ in helium. At least two principal desorption features are evident in the resultant TPD spectra both for $\mathrm{CO}$ and $\mathrm{CO}_{2}$. The total amount of desorbed $\mathrm{CO}$ increases with degree of burn-off, proceeds through a maximum $\mathrm{ca} .30 \%$ burn-off, and then decreases as gasification progresses. On the other hand, the total amount of desorbed $\mathrm{CO}_{2}$ initially increases with burn-off and then becomes relatively constant. Consequently, the micropore surface area is well correlated by desorbed $\mathrm{CO}$, while the desorbed $\mathrm{CO}_{2}$ follows the external surface area reasonably well. It is noted that this is qualitatively the same behavior that we have found for Wyodak coal char samples, as reported in the previous quarterly technical progress report (DE-FG2291PC91305-11).

It is concluded that the smaller, CO-liberating oxygen surface complexes form over the entire surface of the char during gasification, but that the larger, $\mathrm{CO}_{2}$ liberating complexes form only in the larger, external porosity, and correlate with the development of the larger porosity quite well.

\section{References}

Calo,J.M., and Hall,P.J., ACS Div. Fuel Chem. Prepr. 34, No.1, 71(1989).

Calo,J.M., and Hall,P.J., in Fundamental Issues in the Control of Carbon Gasification Reactivity, J.Lahaye and P.Ehrburger, eds, NATO ASI Series, Series E: Applied Sciences, Vol.192, p.329, Kluwer, Dordrecht, 1991.

Gregg, S.J., and Sing, K.S.W., Adsorption, Surface Area and Porosity, Academic Press, London, 1982.

Lippens, B.C., Linsen, B.G., and de Boer, J.H., J. Catal. 3, 32 (1964). 
Lippens, B.C., and de Boer, J.H., J. Catal. 4, 319 (1965).

Miura, K. and Hashimoto, K., IEC Proc. Des. Dev. 23, 138-145 (1984).

Otake, Y. and Jenkins, R.G., Carbon, 31, 109 (1993).

Rodriguez-Reinoso, F., Martin-Martinez, J.M., Prado-Burguete, C., and McEnaney, B.; J. Phys. Chem. 91, 515-516 (1987).

Roberts.,B.F., J. Coll. Intf. Sci. 23, 266 (1967).

Starsinic, M., Taylor, R.L., Walker, P.L., Jr., and Painter, P.C.,Carbon21, 69 (1983).

Vorres, K.S. Users Handbook for the Argonne Premium Coal Samples, ANL/PCSP-93/1, Department of Energy, Argonne, Illinois, 1993.

Walker, P.L. Jr., in Carbon and Coal Gasification, Figueiredo, Moulijn, eds, NATO ASI Series, 9, 3 (1986).

\subsection{PLANS FOR NEXT REPORTING PERIOD}

Work will continue along the two-pronged mode of attack involving thermal desorptions of oxidized samples in the TPD-MS/TGA system, and porosity characterization using gas adsorption techniques and the analysis of small angle scattering data. Specific plans for the next reporting period include adding to the data set with char samples produced from a non-mineral matter-containing phenolformaldehyde resin. The nature of the secondary interactions (i.e., secondary $\mathrm{CO}_{2}$ formation and $\mathrm{CO}$ rechemisorption) will be further investigated primarily via studies of the behavior of these features as a function of heating rate. 


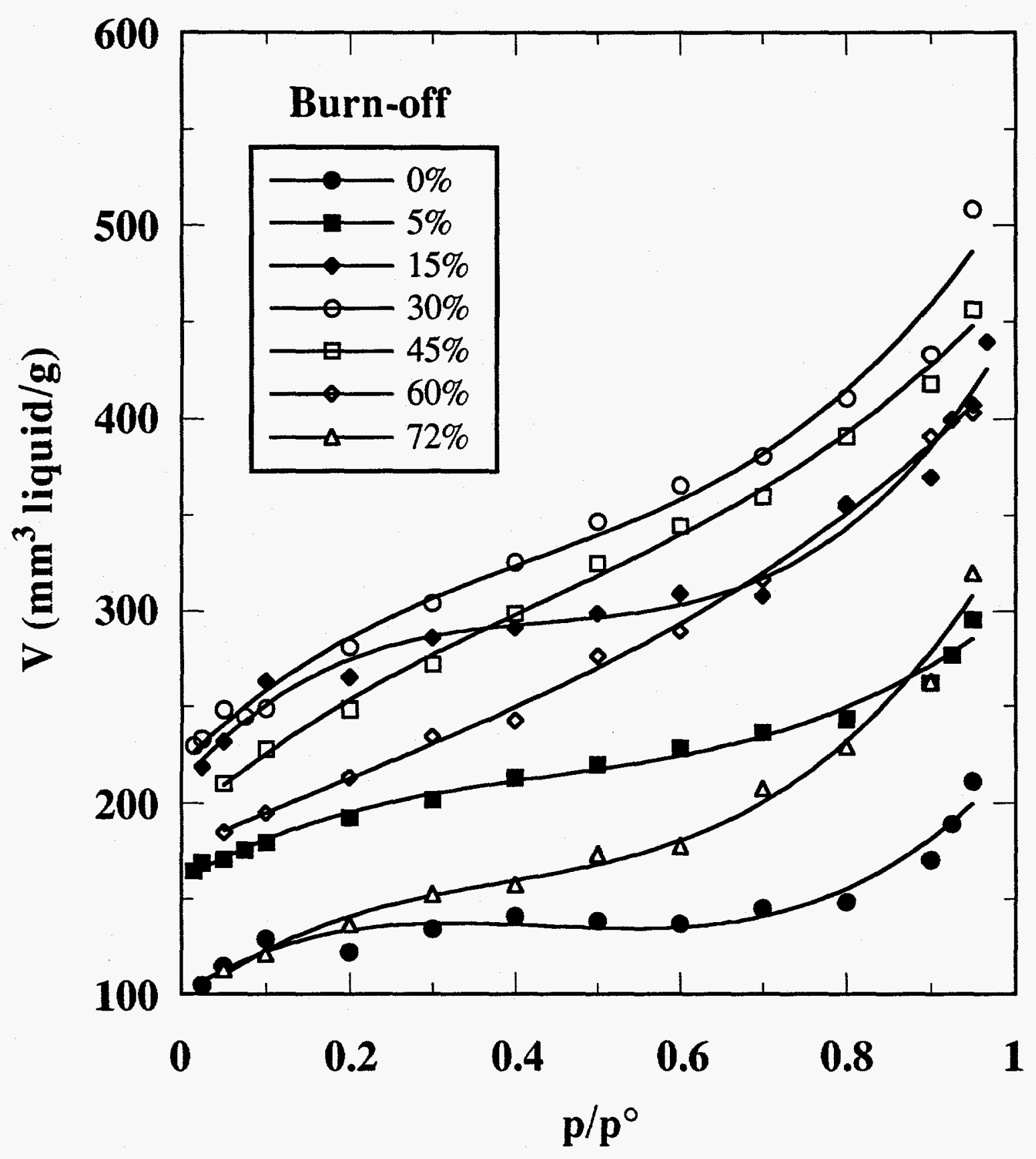

Figure 1. Nitrogen adsorption isotherms for Wyodak coal char as a function of burn-off in $0.1 \mathrm{MPa}$ of oxygen at $420^{\circ} \mathrm{C}$. 


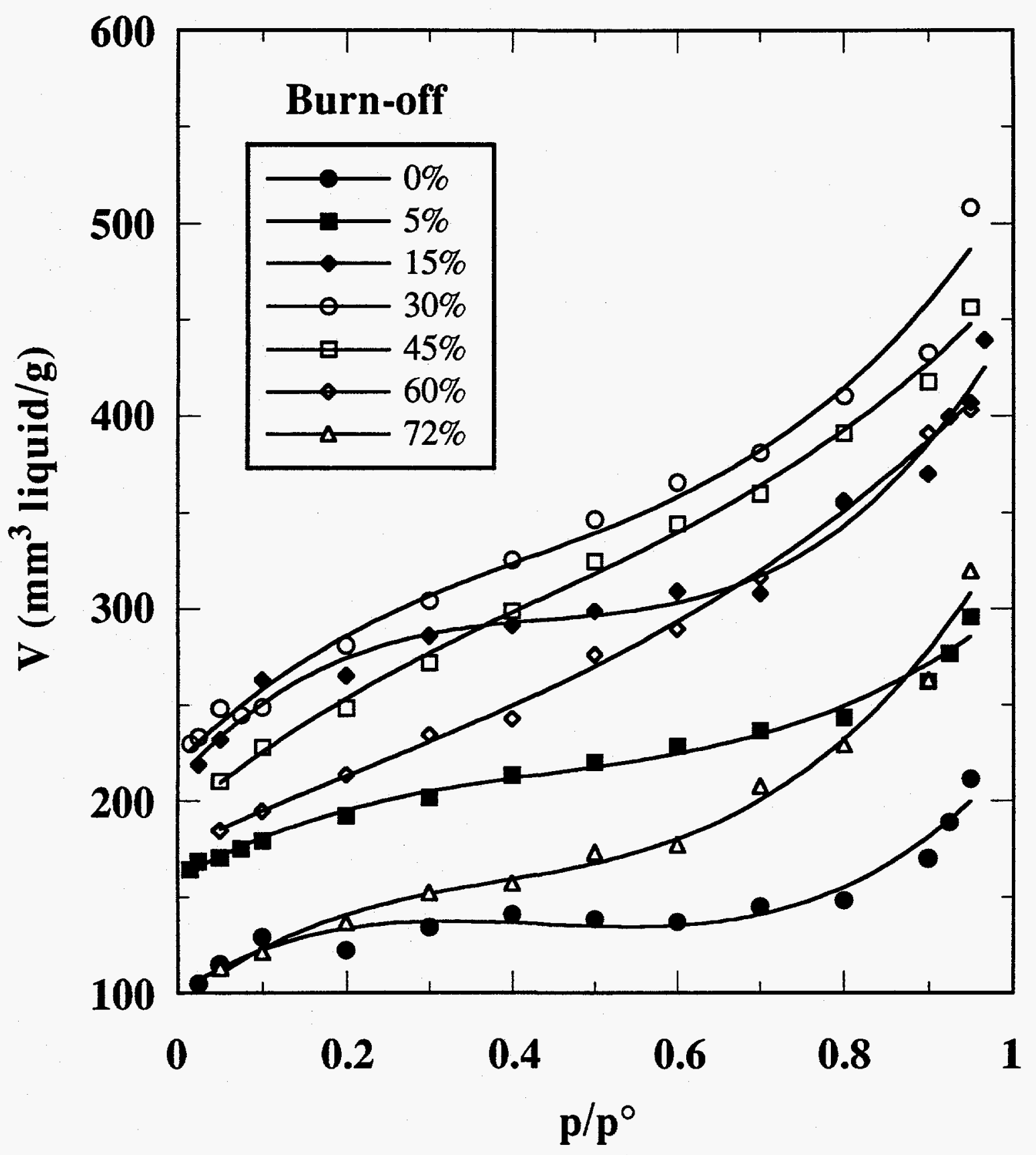

Figure 2. Nitrogen adsorption isotherms for Wyodak coal char as a function of burn-off in $0.1 \mathrm{MPa}$ of oxygen at $420^{\circ} \mathrm{C}$. 


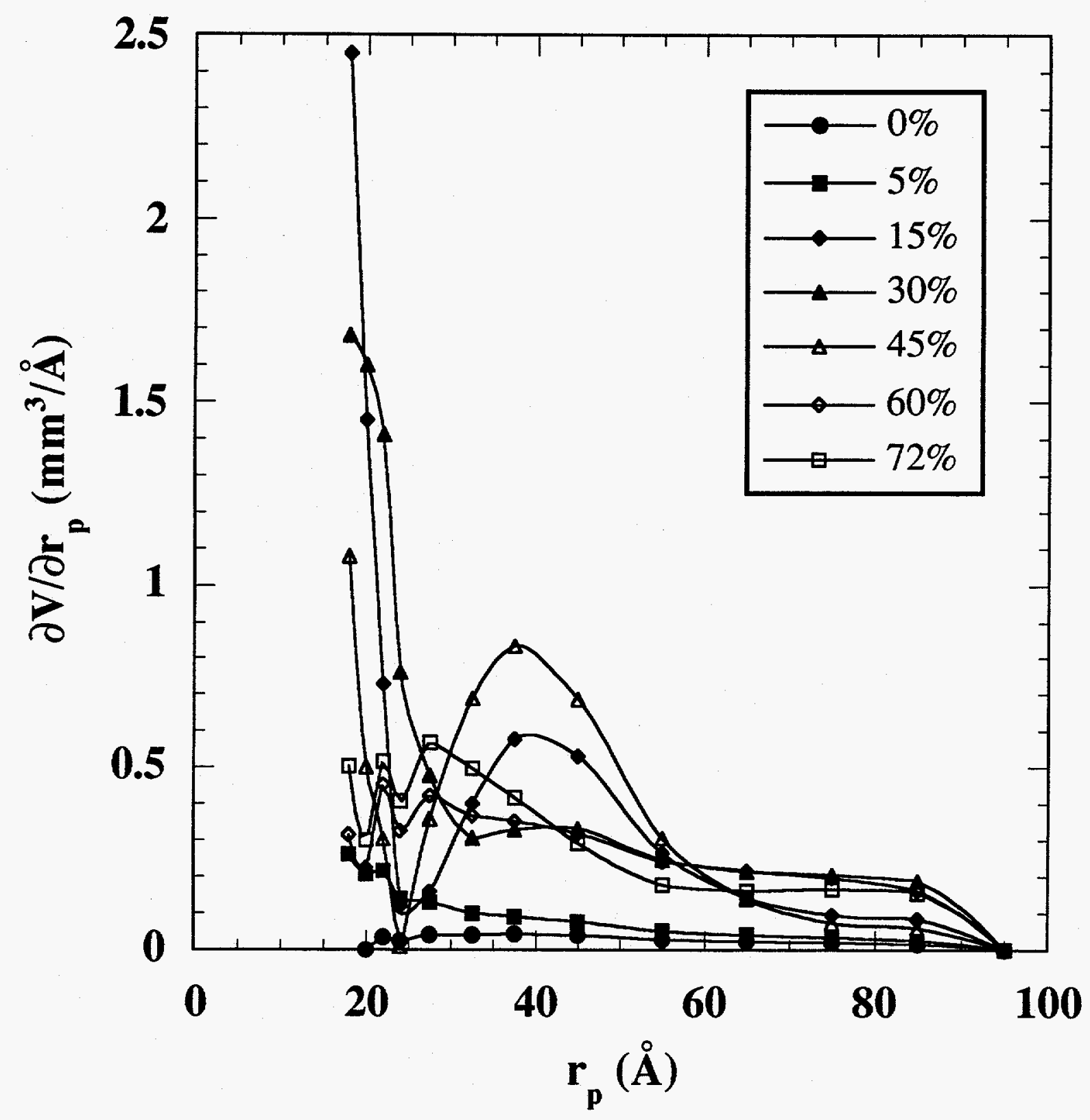

Figure 3. Pore size distributions for Pittsburgh \#8 coal char samples as a function of burn-off, determined according to the method of Roberts (1967). 


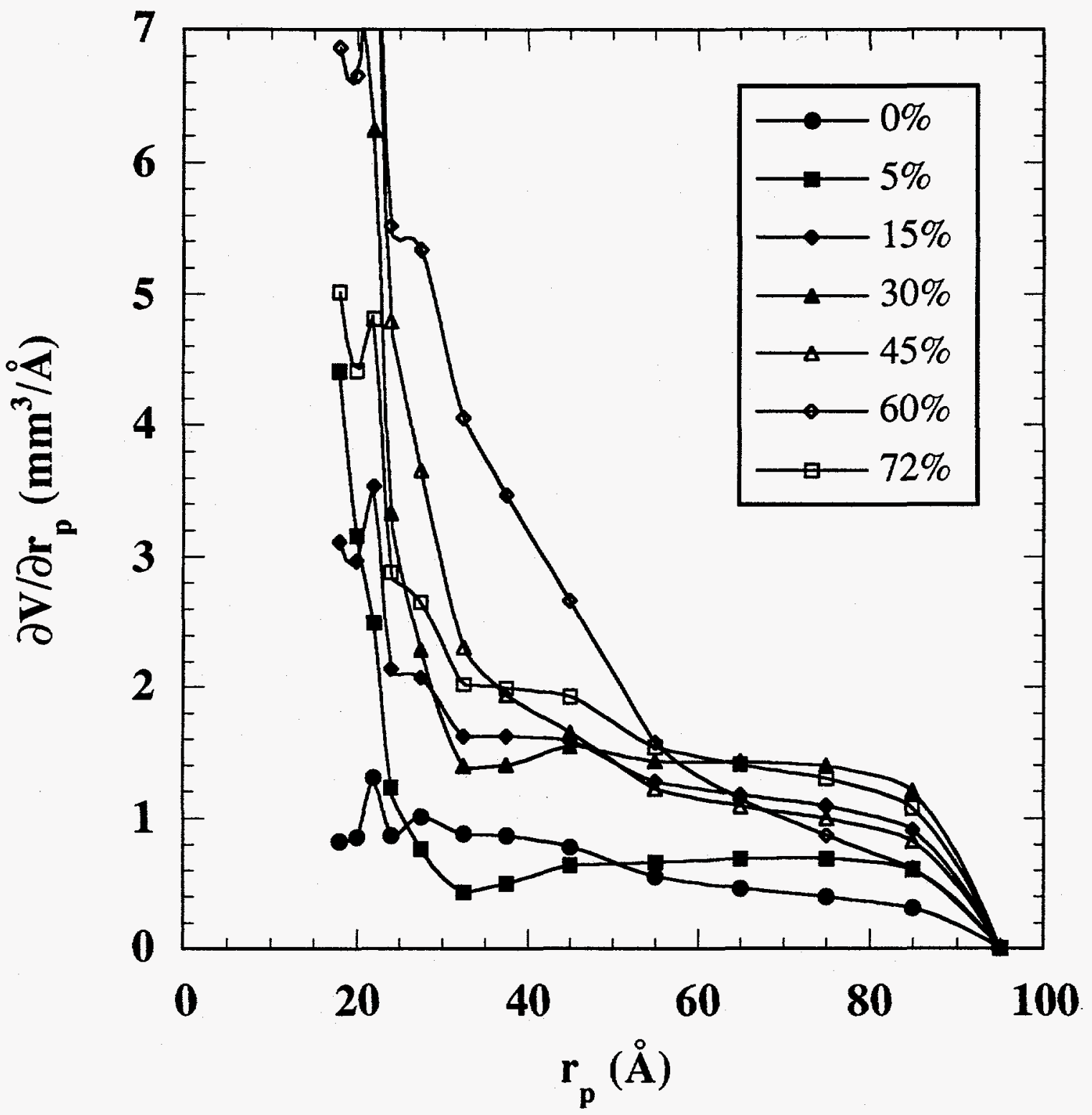

Figure 4. Pore size distributions for Wyodak coal char samples as a function of burn-off, determined according to the method of Roberts (1967). 


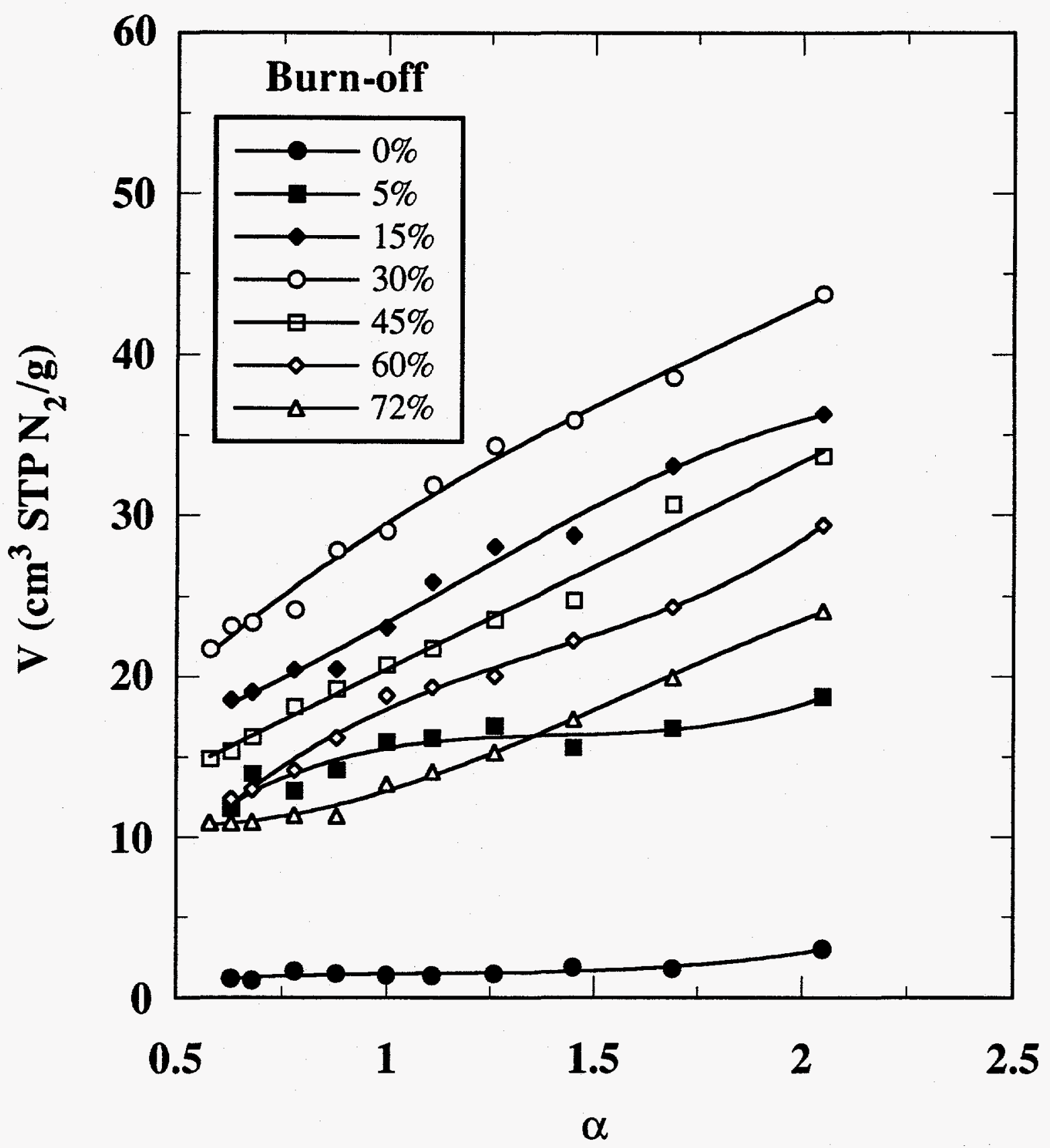

Figure 5. Alpha-plots for Pittsburgh \#8 coal char as a function of burn-off in $0.1 \mathrm{MPa}$ of oxygen at $470^{\circ} \mathrm{C}$. 


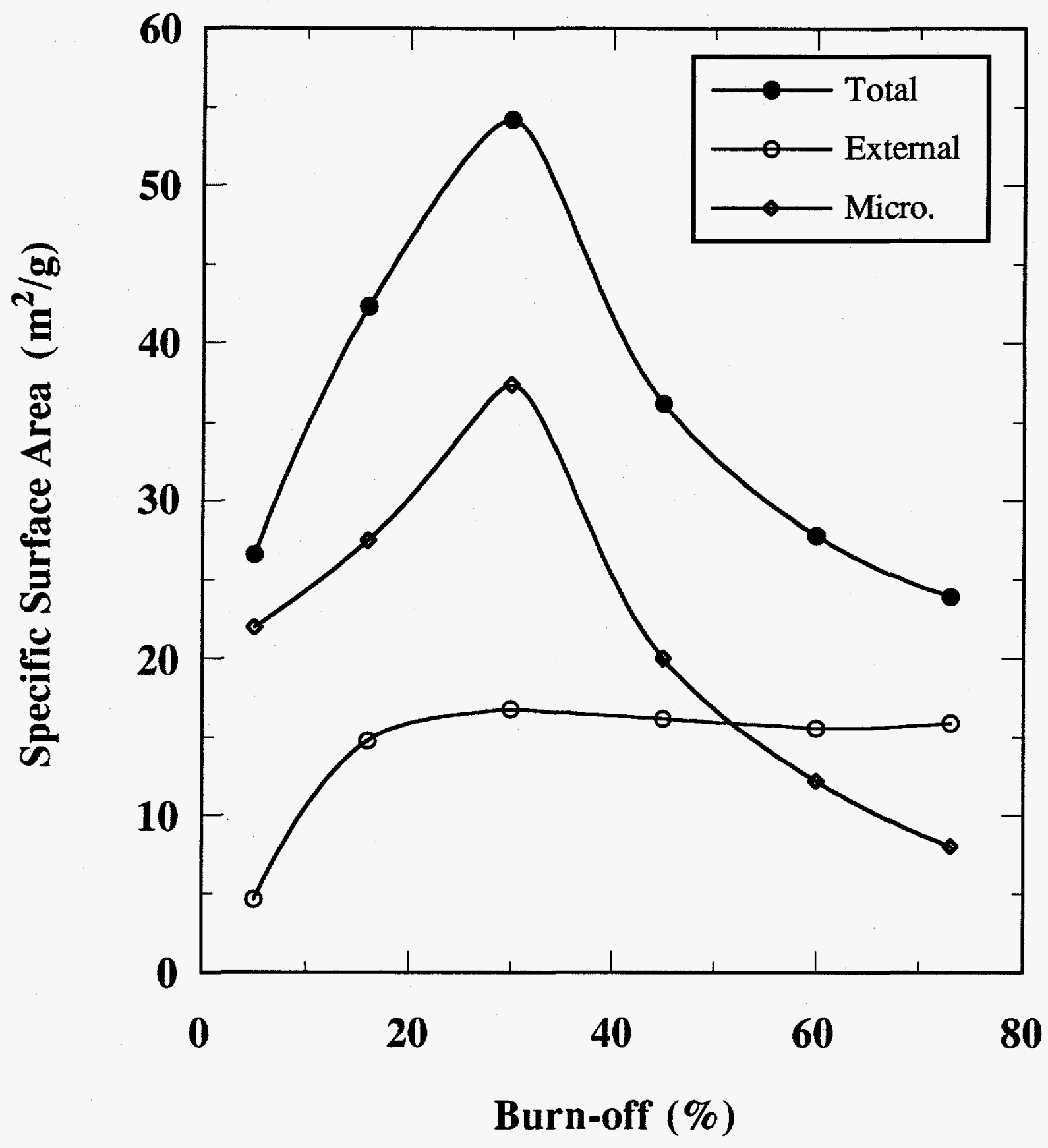

Figure 6. Variation of total, nonmicroporous (external) and microporous surface area with burn-off for Pittsburgh \#8 coal char gasified in $0.1 \mathrm{MPa}$ of oxygen at $470^{\circ} \mathrm{C}$. 


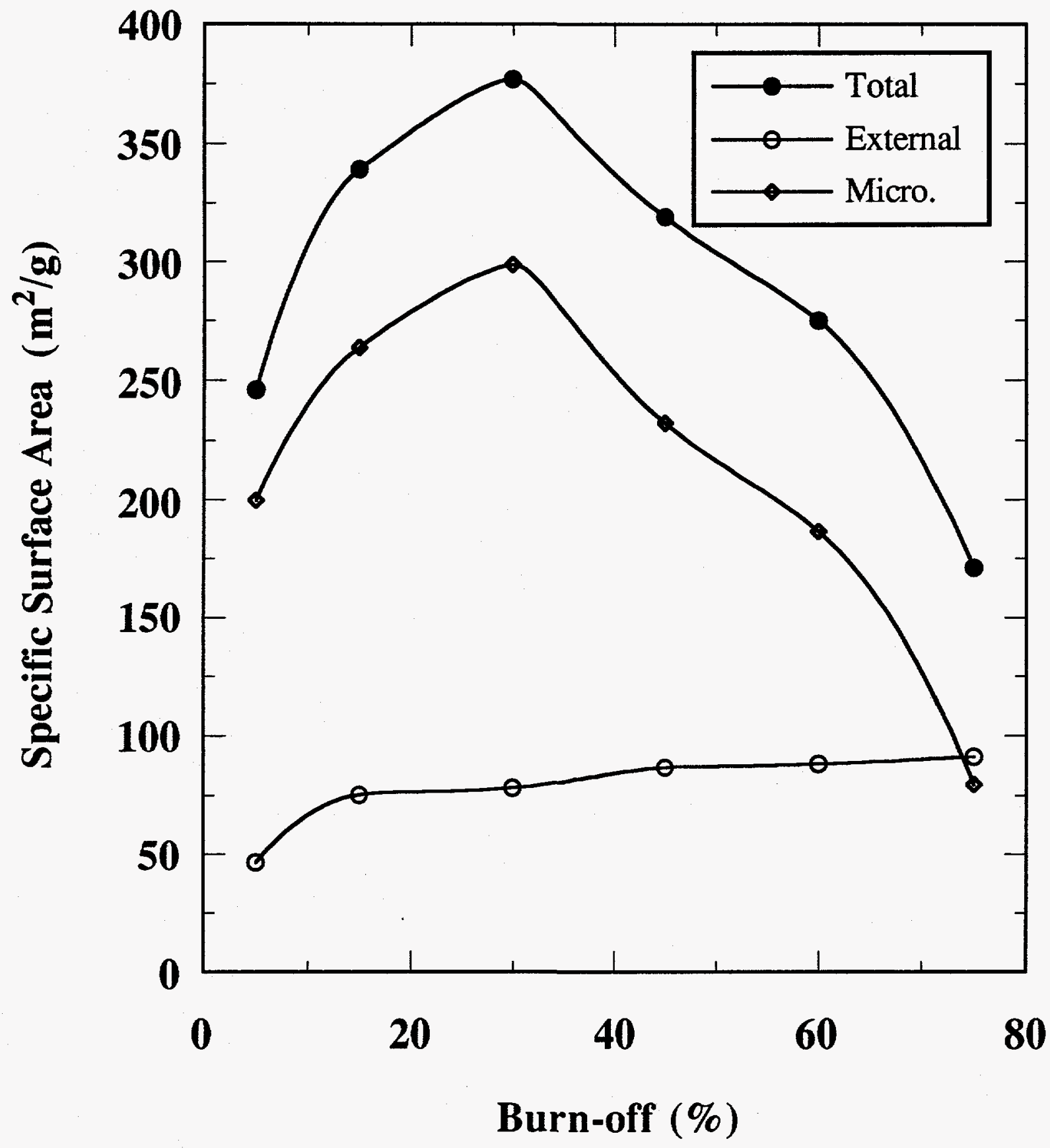

Figure 7. Variation of total, nonmicroporous (external) and microporous surface area with burn-off for Wyodak coal char gasified in $0.1 \mathrm{MPa}$ of oxygen at $420^{\circ} \mathrm{C}$. 


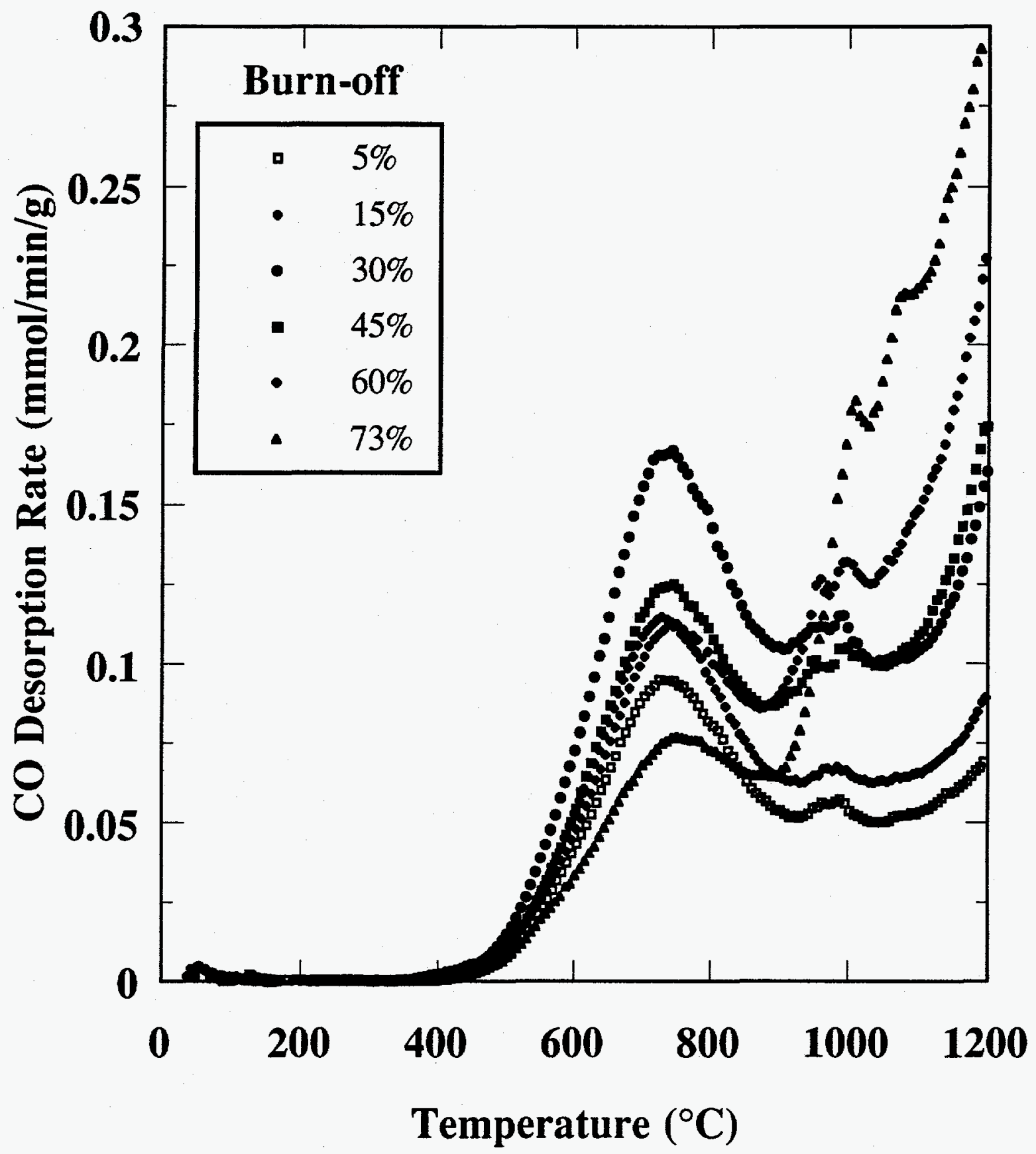

Figure $8.50 \mathrm{~K} / \mathrm{min} \mathrm{CO}$ spectra from Pittsburgh \#8 coal char as a function of burn-off in $0.1 \mathrm{MPa}$ of oxygen at $470^{\circ} \mathrm{C}$. 


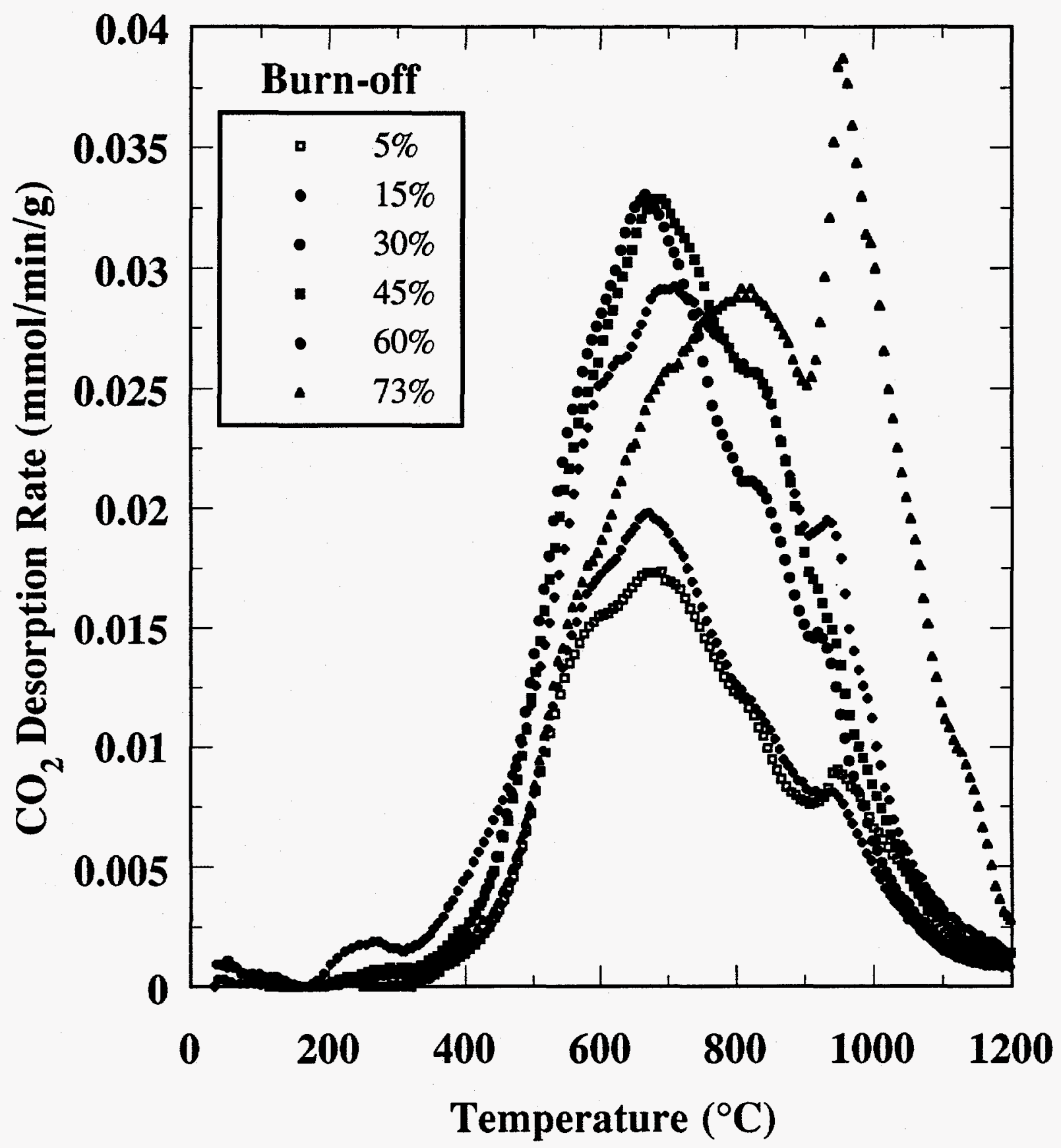

Figure 9. 50K/min $\mathrm{CO}_{2}$ spectra from Pittsburgh \#8 coal char as a function of burn-off in $0.1 \mathrm{MPa}$ of oxygen at $470^{\circ} \mathrm{C}$. 


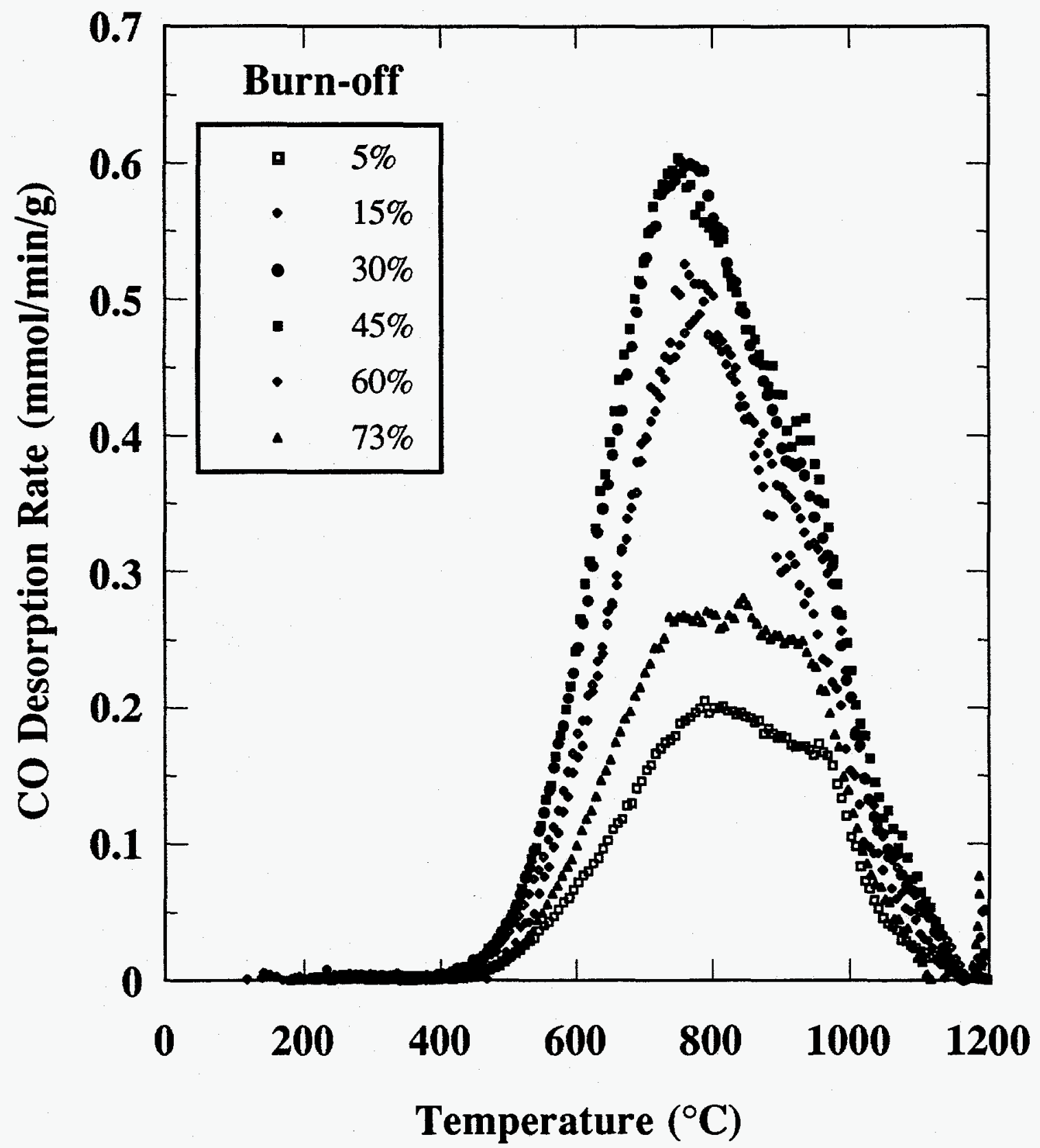

Figure $10.50 \mathrm{~K} / \mathrm{min} \mathrm{CO}$ spectra from Wyodak coal char as a function of burn-off in $0.1 \mathrm{MPa}$ of oxygen at $420^{\circ} \mathrm{C}$. 


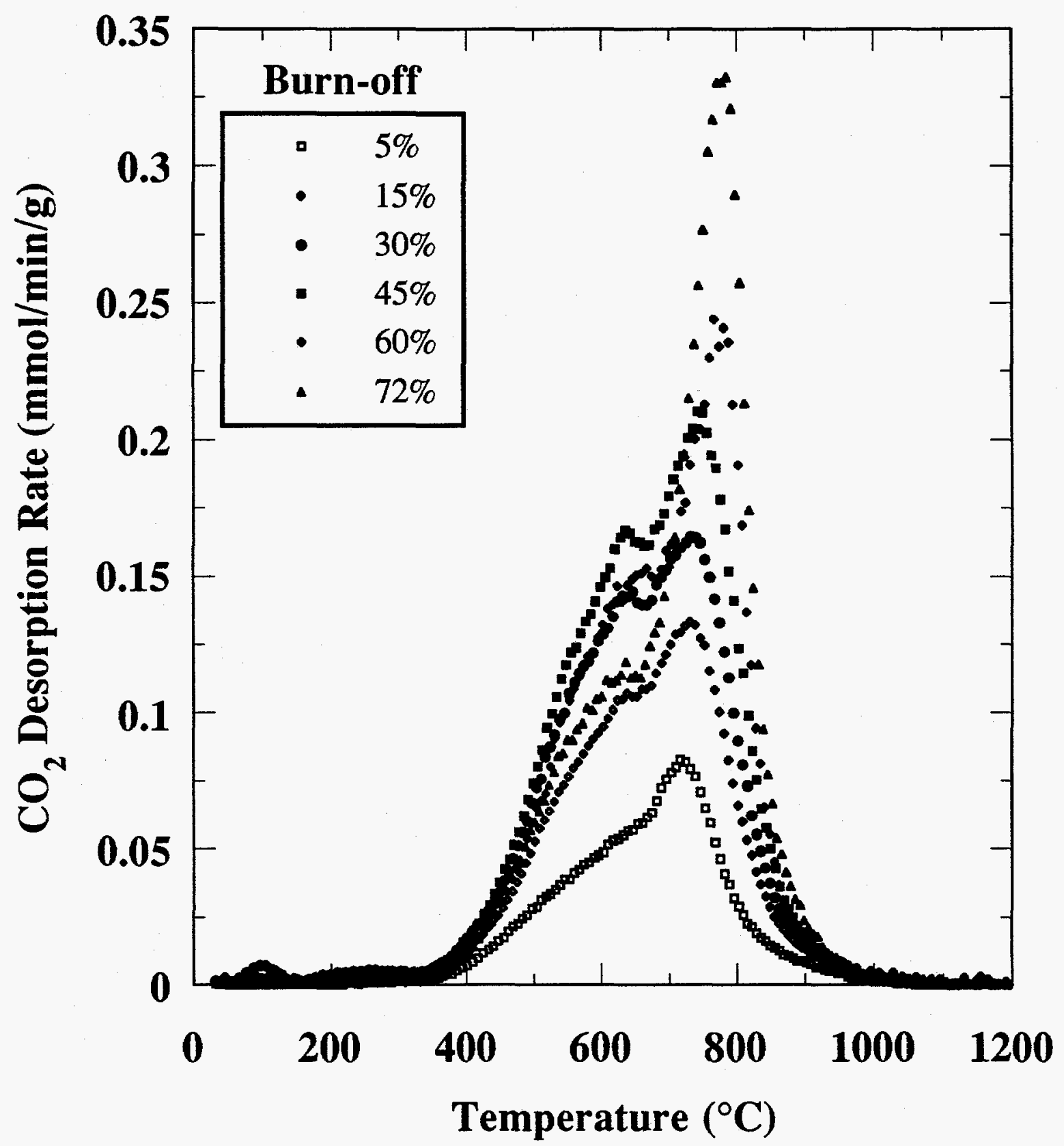

Figure $11.50 \mathrm{~K} / \mathrm{min} \mathrm{CO}_{2}$ spectra from Wyodak coal char as a function of burn-off in $0.1 \mathrm{MPa}$ of oxygen at $420^{\circ} \mathrm{C}$. 


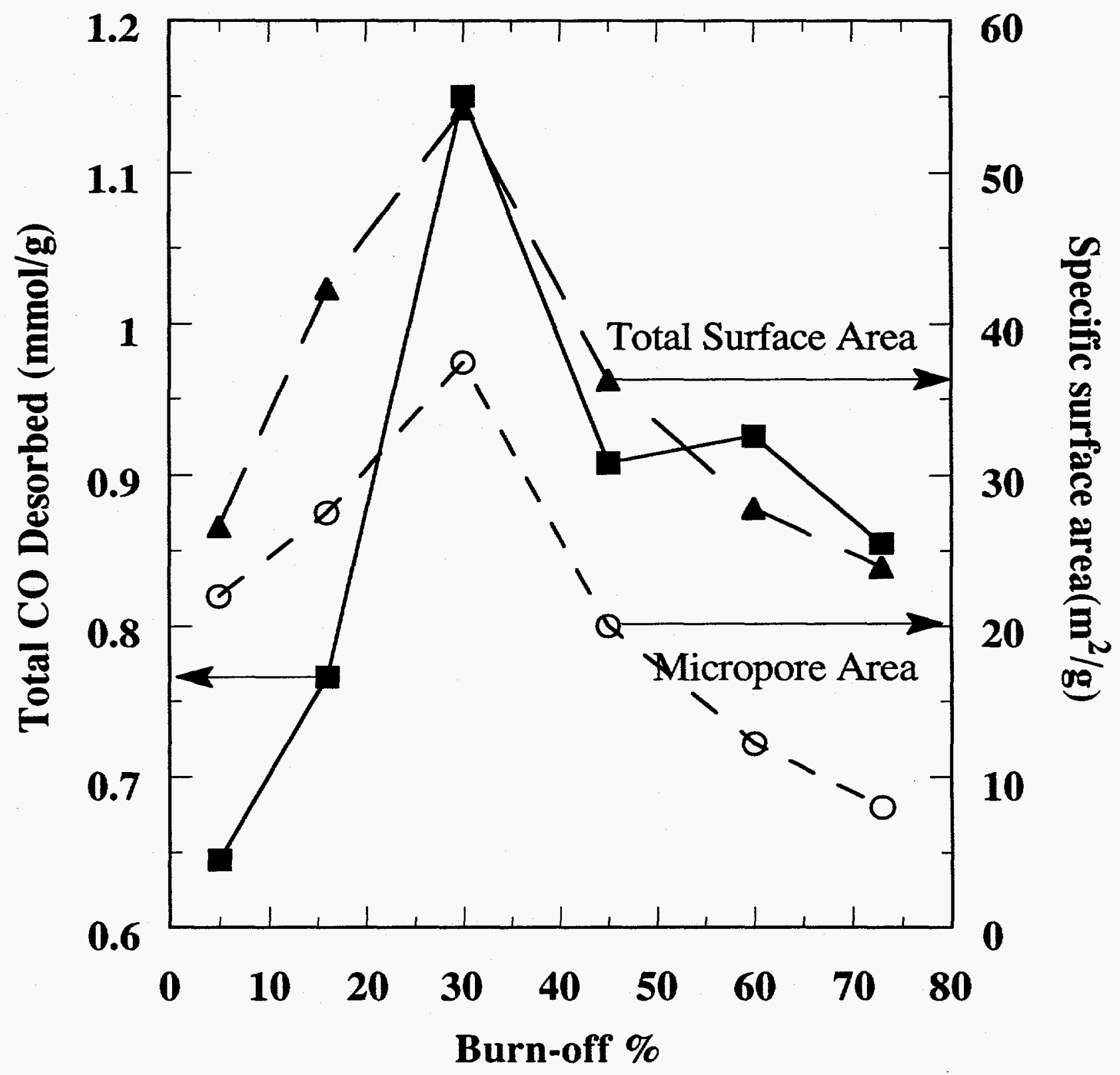

Figure 12. Comparison of total and micropore surface areas and total CO desorbed as a function of burn-off for Pittsburgh \#8 coal char gasified in $0.1 \mathrm{MPa}$ oxygen at $470^{\circ} \mathrm{C}$. 


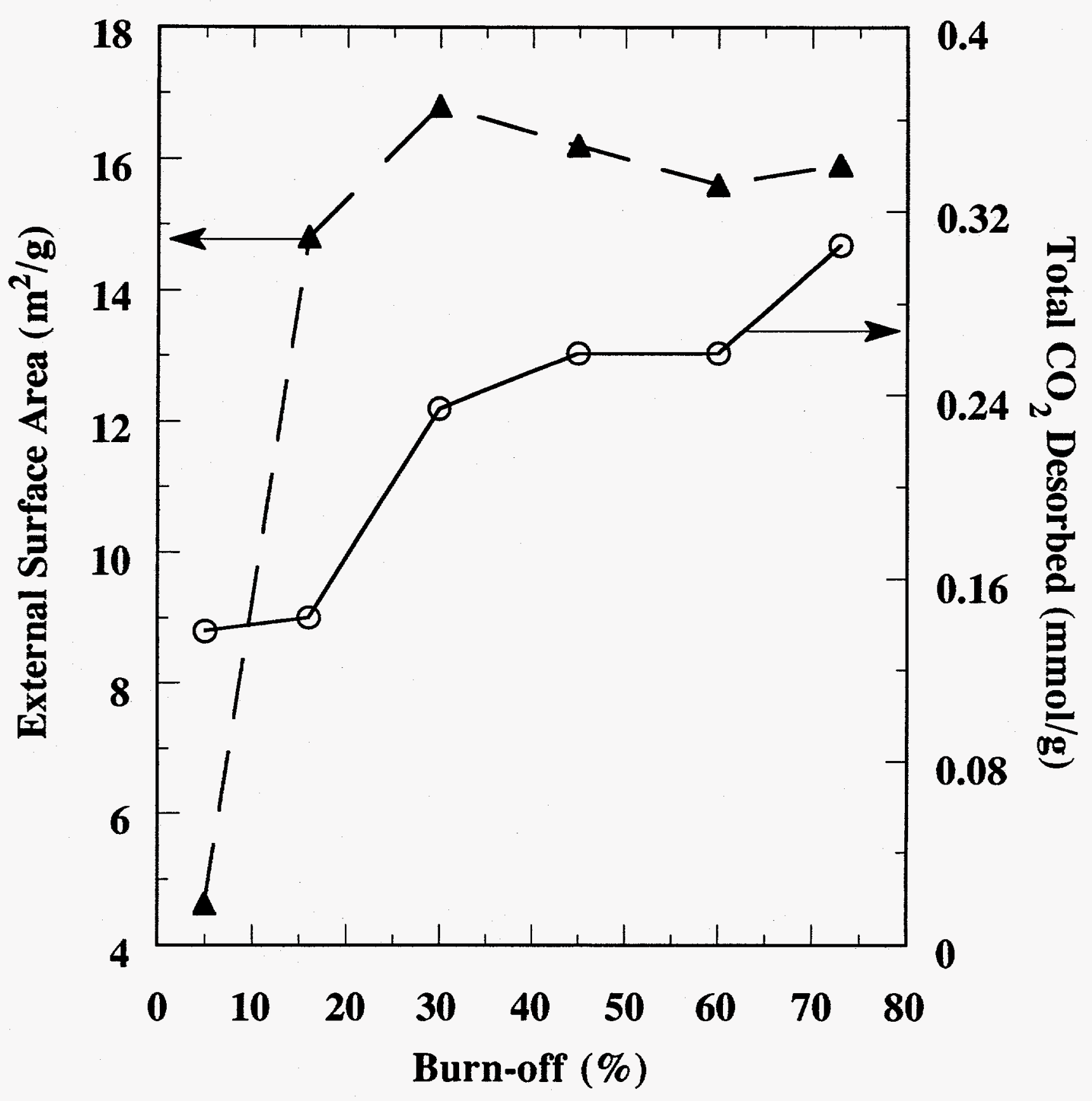

Figure 13. Comparison of external surface area and $\mathrm{CO}_{2}$ desorbed as a function of burn-off for Pittsburgh \#8 coal char gasified in oxygen at $470^{\circ} \mathrm{C}$. 


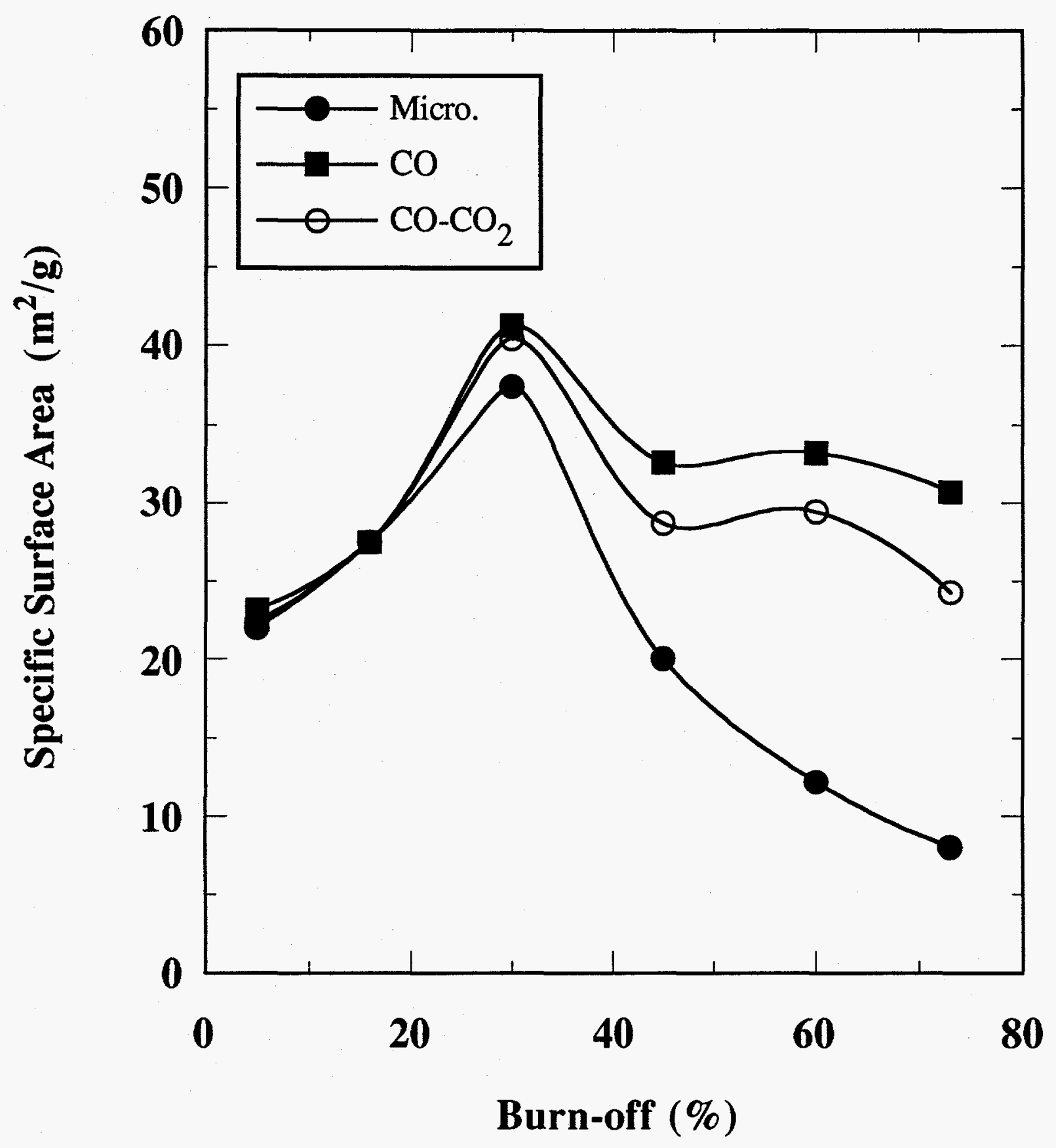

Figure 14. Comparison of microporous surface area, total $\mathrm{CO}$ desorbed, and total $\mathrm{CO}$ minus total $\mathrm{CO}_{2}$ desorbed as a function of burn-off for the Pittsburgh \#8 coal char data. (Gas desorption data normalized to surface area at $15 \%$ burn-off.) 
Appendix A. Roberts' Method for Pore Size Distributions

Pore Size Distribution Calculation - Roberts Method - 15\% Burn-off Pittsburgh \#8

$\begin{array}{llllllllllllllll}\text { Pore group } & 13 & 12 & 11 & 10 & 9 & 8 & 7 & 6 & 5 & 4 & 3 & 2 & 1 & 0\end{array}$

$\begin{array}{lllllllllllllll}\mathrm{rp} / \AA & 17 & 19 & 21 & 23 & 25 & 30 & 35 & 40 & 50 & 60 & 70 & 80 & 90 & 100\end{array}$

$\begin{array}{lrrrrrrrrrrrrr}\mathrm{rbp} / \AA & 18 & 20 & 22 & 24 & 27.5 & 32.5 & 37.5 & 45 & 55 & 65 & 75 & 85 & 95 \\ \mathrm{t} / \AA & 5.5 & 5.85 & 6.2 & 6.3 & 6.6 & 7.05 & 7.5 & 7.8 & 8.6 & 9.2 & 9.8 & 10.5 & 11.7\end{array}$

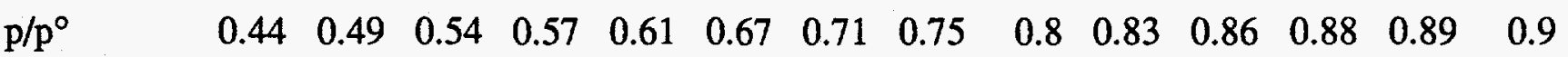

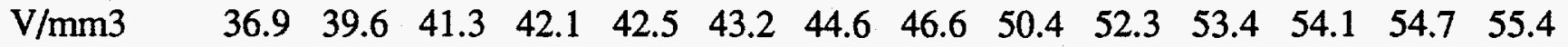

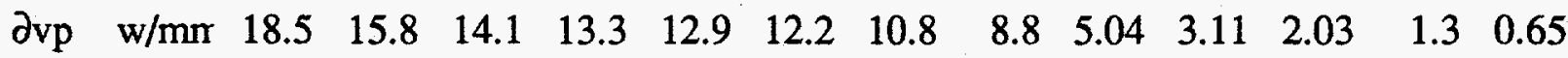

\begin{tabular}{|c|c|c|c|c|c|c|c|c|c|c|c|c|c|c|c|}
\hline 2.9 & 12 & $\begin{array}{r}526 \\
1.52\end{array}$ & & & & & & & & & & & & & \\
\hline \multirow[t]{2}{*}{1.45} & 11 & 563 & 539 & & & & & & & & & & & & \\
\hline & & 0.82 & 0.78 & & & & & & & & & & & & \\
\hline \multirow[t]{2}{*}{0.23} & 10 & 594 & 572 & 550 & & & & & & & & & & & \\
\hline & & 0.14 & 0.13 & 0.13 & & & & & & & & & & & \\
\hline \multirow[t]{2}{*}{0.78} & 9 & 640 & 620 & 600 & 594 & & & & & & & & & & \\
\hline & & 0.5 & 0.48 & 0.47 & 0.46 & & & & & & & & & & \\
\hline \multirow[t]{2}{*}{2} & 8 & 690 & 672 & 655 & 650 & 635 & & & & & & & & & \\
\hline & & 1.38 & 1.34 & 1.31 & 1.3 & 1.27 & & & & & & & & & \\
\hline \multirow{2}{*}{2.88} & 7 & 728 & 712 & 697 & 692 & 679 & 659 & & & & & & & & \\
\hline & & 2.1 & 2.05 & 2.01 & 1.99 & 1.96 & 1.9 & & & & & & & & \\
\hline \multirow[t]{2}{*}{5.3} & 6 & 770 & 757 & 743 & 740 & 728 & 711 & 694 & & & & & & & \\
\hline & & 4.08 & 4.01 & 3.94 & 3.92 & 3.86 & 3.77 & 3.68 & & & & & & & \\
\hline \multirow[t]{2}{*}{2.64} & 5 & 810 & 799 & 787 & 784 & 774 & 760 & 746 & 736 & & & & & & \\
\hline & & 2.14 & 2.11 & 2.08 & 2.07 & 2.04 & 2.01 & 1.97 & 1.94 & & & & & & \\
\hline \multirow[t]{2}{*}{1.41} & 4 & 838 & 828 & 818 & 816 & 807 & 795 & 783 & 774 & 753 & & & & & \\
\hline & & 1.18 & 1.17 & 1.16 & 1.15 & 1.14 & 1.12 & 1.11 & 1.09 & 1.06 & & & & & \\
\hline \multirow[t]{2}{*}{0.93} & 3 & 859 & 850 & 842 & 839 & 832 & 821 & 810 & 803 & 784 & 770 & & & & \\
\hline & & 0.8 & 0.79 & 0.79 & 0.78 & 0.78 & 0.77 & 0.76 & 0.75 & 0.73 & 0.72 & & & & \\
\hline \multirow[t]{2}{*}{0.82} & 2 & 875 & 867 & 859 & 857 & 851 & 841 & 831 & 825 & 808 & 795 & 783 & & & \\
\hline & & 0.72 & 0.71 & 0.71 & 0.7 & 0.7 & 0.69 & 0.68 & 0.68 & 0.66 & 0.65 & 0.64 & & & \\
\hline \multirow[t]{2}{*}{0.85} & 1 & 888 & 881 & 874 & 872 & 866 & 857 & 848 & 843 & 827 & 816 & 804 & 791 & & \\
\hline & & 0.76 & 0.75 & 0.74 & 0.74 & 0.74 & 0.73 & 0.72 & 0.72 & 0.7 & 0.69 & 0.68 & 0.67 & & \\
\hline \multirow[t]{2}{*}{ Qii } & & 2.07 & 2 & 1.94 & 1.84 & 1.73 & 1.63 & 1.56 & 1.46 & 1.41 & 1.36 & 1.32 & 1.3 & 1.3 & \\
\hline & & 2 & 2 & 2 & 2 & 5 & 5 & 5 & 10 & 10 & 10 & 10 & 10 & 10 & 10 \\
\hline \multicolumn{2}{|l|}{ B } & 16.1 & 14.3 & 13.3 & 13.1 & 12.5 & 11 & 8.91 & 5.18 & 3.16 & 2.07 & 1.33 & 0.67 & & \\
\hline \multicolumn{2}{|c|}{$C=w-B$} & 2.36 & 1.45 & 0.75 & 0.13 & 0.45 & 1.23 & 1.84 & 3.62 & 1.88 & 1.04 & 0.71 & 0.63 & & \\
\hline \multicolumn{2}{|c|}{$\partial v p=Q i i C$} & 4.9 & 2.9 & 1.45 & 0.23 & 0.78 & 2 & 2.88 & 5.3 & 2.64 & 1.41 & 0.93 & 0.82 & & \\
\hline \multicolumn{2}{|c|}{$\partial v \mathrm{p} / \partial \mathrm{rp}$} & 2.45 & 1.45 & 0.73 & 0.12 & 0.16 & 0.4 & 0.58 & 0.53 & 0.26 & 0.14 & 0.09 & 0.08 & & \\
\hline
\end{tabular}

